\title{
Effect of Music on Quality of Life in Stable Angina: A Randomized Controlled Trial
}

\author{
Samitha Siritunga ${ }^{{ }^{*}}$, Kumudu Wijewardena ${ }^{2}$, Ruwan Ekanayaka3 \\ Premadasa Mudunkotuwa ${ }^{4}$ \\ ${ }^{1}$ Non Communicable Disease Unit, Ministry of Health, Colombo, Sri Lanka \\ ${ }^{2}$ Department of Community Medicine, Faculty of Medical Sciences, University of Sri Jayawardhanapura, \\ Nugegoda, Sri Lanka \\ ${ }^{3}$ Institute of Cardiology, National Hospital, Colombo, Sri Lanka \\ ${ }^{4}$ Department of Languages and Cultural studies University of Sri Jayawardhanapura, Nugegoda, Sri Lanka \\ Email: sssiritunga@yahoo.com
}

Received 24 March 2015; accepted 15 May 2015; published 18 May 2015

Copyright (C) 2015 by authors and Scientific Research Publishing Inc.

This work is licensed under the Creative Commons Attribution International License (CC BY).

http://creativecommons.org/licenses/by/4.0/

(c) (i) Open Access

\section{Abstract}

Introduction: Quality of life associated with coronary artery disease can be affected by number of factors. Even though standard treatment has improved survival of such patients, the quality of life may be less than ideal as the disease affects the physical, social, and emotional functioning of such individuals. Therefore improvement of the quality of life of the patients with coronary artery disease is vital. Though music has been identified having a potential benefit in improving quality of life for many years, researches conducted to recognize the effect of music on quality of life were sparse. Therefore the aim of this study was to determine the effect of frequent long term listening to Indian classical music on quality of life in chronic stable angina (SA) patients. Methodology: This single blind randomized clinical trial was conducted for one month. The intervention group of 30 patients listened to a music based on Indian classical system at home twice a day complementary to their regular treatment. The control group of 30 was only on their usual treatment. Both groups were assessed before and after the intervention for the quality of life by the Sinhala version of SF-36 questionnaire. Results: A statistically significant increase of scores for physical function by $16.17(p<0.01)$, for role-physical $-40.83(p<0.01)$, for body pain-11.03 $(p<0.01)$, for general health-17.9 $(p<0.01)$, for vitality-17 ( $<<0.01)$, for social functioning-15.37, for role emotional-37.87 ( $p<0.01)$, for mental health-16.66 ( $p<0.01)$, overall physical health by 20.6 ( $p<$ $0.01)$, the overall mental health by $20.84(\mathrm{p}<0.01)$ and the total score of quality of life by $21.6(\mathrm{p}<$ 0.01) was observed in the study group after the intervention; but not in the control group. Conclusion: Listening to the music based on Indian classical system significantly improved the quality of life of stable angina patients. Therefore music therapy has a potential benefit in considering for

\footnotetext{
"Corresponding author.
}

How to cite this paper: Siritunga, S., Wijewardena, K., Ekanayaka, R. and Mudunkotuwa, P. (2015) Effect of Music on Quality of Life in Stable Angina: A Randomized Controlled Trial. International Journal of Clinical Medicine, 6, 307-313. 
use as complementary to conventional treatment for stable angina in improving quality of life.

\section{Keywords}

Music, Music Therapy, Relaxing Music, Indian Classical, Stable Angina, Quality of Life, SF-36

\section{Introduction}

Myocardial Infarction (MI) affects not only the physical health of the patient, but also the emotional, social and functional aspects of life. Consequently, the views of the patient may be different compared to the view of the clinician regarding the success of management. Therefore, management of MI which is considered as a success by the clinician may not be perceived in the same way by the patient or by the patient's family. Hence the aim of treating MI should not only be to minimize the morbidities and mortalities related to MI, but also to uplift the quality of life (QoL) of the patient [1]-[3]. QoL of the MI patients can be affected by number of factors associated with MI such as emotional and physical distress, depression, other comorbidities in addition to the drugs and other management procedures used in the treatment [3] [4]. Though the prognosis after MI has improved dramatically with the advances of management during last few decades [5] [6], the QoL of the patients is adversely affected [4] [7]. Therefore, improving QoL after myocardial infarction remains a challenge for physicians and it has to be taken into consideration when assessing the improvement after medical or surgical treatment.

\section{Relaxing Music and Quality of Life of Ischaemic Heart Disease}

Relaxing music has been used for centuries to promote healing, to enhance the QoL and it is often used in the management of stress [8]. It is considered as a complementary therapy along with other treatments to help patients cope mentally and physically with their diagnosis [9]. But no published data are available in use of relaxing music as a method of improving the QoL of post MI patients.

Effect of relaxing music has been thought to be due to a complex neurophysiological phenomenon which affects entire nervous system and the stress hormones [10]. Through these mechanisms it reduces the rate of formation of the atheromatous plaque, the metabolic rate, heart rate, blood pressure, free fatty acids and oxygen consumption and hence, music therapy reduces the severity of the disease [11] [12]. Additionally, as it relieves pain through endorphins secreted from the pituitary gland and affects the higher centres of the brain such as cerebral cortex and limbic system, music therapy would enhance the disease related QoL. As music therapy is relatively inexpensive [13], considered safe and has no side effects [14], it is easy to practice and more accepted by the general population. Therefore, if it could be considered in the management of patients with ischaemic heart disease, it would help to reduce the health related cost associated with cardio vascular disease related problems which would consume the largest proportion of the health budget in future especially in low and middle income countries [15]-[17]. Therefore the aim of this study was to determine the effect of frequent long term listening to Indian classical music on quality of life in chronic stable angina (SA) patients.

\section{Methodology (Figure 1)}

This study was an extension of a single blind randomised controlled trial conducted to investigate the effect of music on symptoms and state of ischaemia in SA [18] [19].

This was conducted at the coronary care unit, National Hospital, Sri Lanka from May 2007 to June 2008. Ethical approval was obtained from the ethics review committee of University of Sri Jayawardhanapura, Sri Lanka. Those who assessed and analysed the outcome were blinded to patient treatment status.

The estimated sample size was 60 calculated for the effect size of $20 \%$ from the base line of the time taken to $1 \mathrm{~mm}$ ST segment depression in exercise ECG at $\alpha=0.05$ and power at $0.8(80 \%)$.

Both male and female patients between 45 to 65 years of age with clinically diagnosed chronic stable angina confirmed by exercise ECG using Bruce protocol were selected as the sample. Patients who had any other heart 


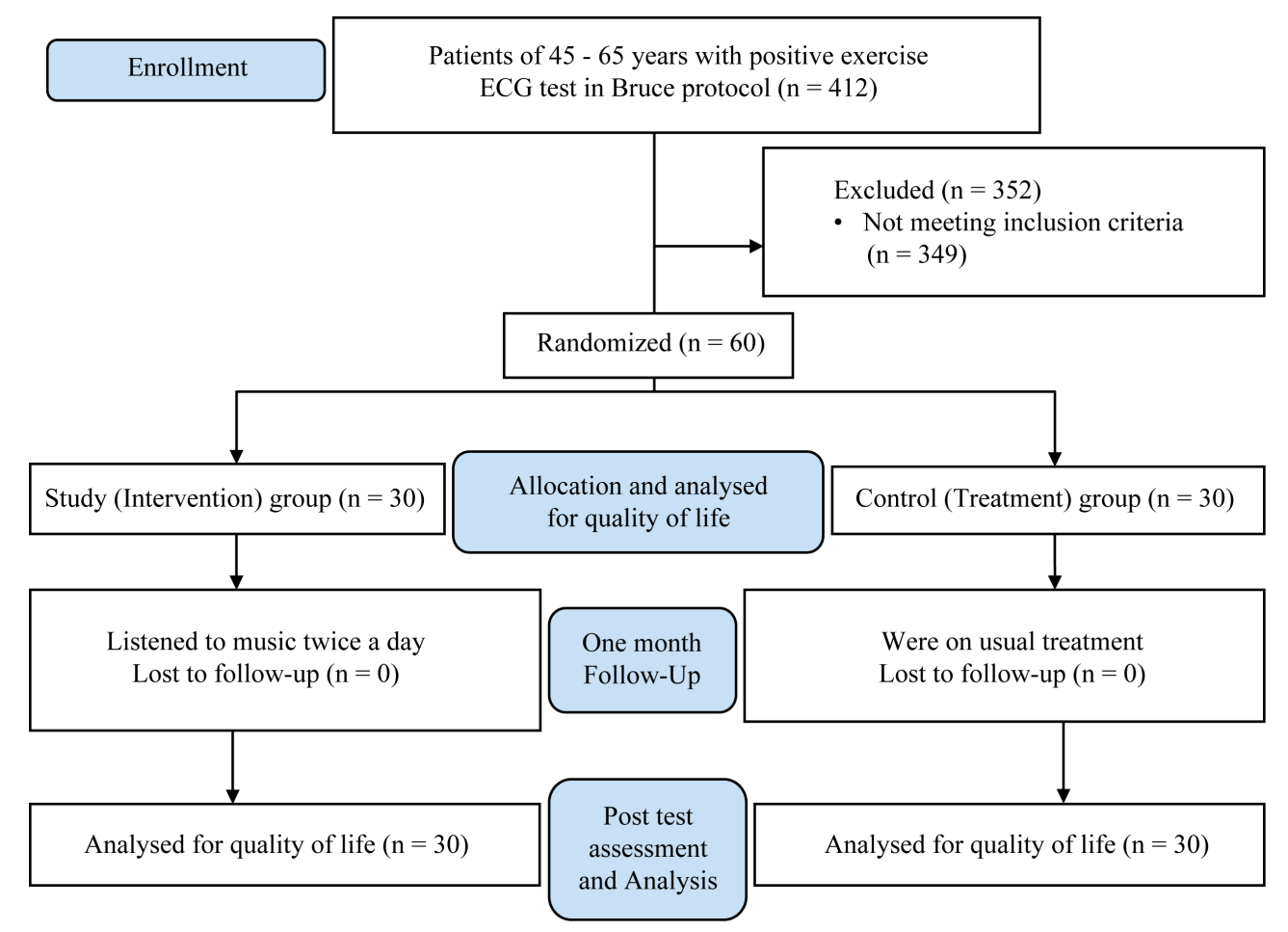

Figure 1. Methodology.

diseases or any other chronic medical or psychological illness and whose clinical condition was not stable which would require frequent change of the treatment were excluded. After assessing the eligibility of 412 patients of 45 - 65 years of age with positive exercise ECG, 60 patients were selected for the study (352 patients were excluded-349 did not meet the selection criteria and 3 refused for participation). 30 patients were recruited to each intervention (study) and control (treatment only) groups by restricted randomisation technique with the allocation ratio of $1: 1$ after obtaining the informed written consent.

\subsection{Intervention}

The intervention period was one month. The intervention group was provided an audio compact disc (CD) with a music based on Indian classical Rag DarbariKanada which lasts about 22 minutes to listen till the end of the track complementary to their usual medicines for a period of one month. According to the empirical studies, this rag has shown a positive effect on cardio vascular system [20]. Patients listened to music twice a day preferably early in the morning and in the evening using either ear or head phones. Special measures were taken to ensure the compliance of the study individuals. During the whole period of one month, the control group was kept only on their usual medicines.

\subsection{Data Collection}

Data were obtained from the participants at the time of recruitment for the study (Pre test) and after the completion of intervention period (Post test). QoLwas assessed by using the validated version of health related quality of life questionnaire Short form-36 (SF-36). Eight basic components of quality of life viz. physical function, role physical, body pain, general health, vitality, social functioning, role emotional and mental health were measured. Moreover summary measurements such as overall physical health, mental health and the total score were also assessed.

Each component of SF-36 questionnaire was analysedusing the standard scoring system provided with the questionnaire. Scores are ranged from 1 - 100 for each component. To analyse the data, independent or paired $t$ tests were used where applicable. The significant level of a statistical test was considered as 0.01 and 0.05 . Significance obtained from the statistical tests $\leq 0.01$ were all considered as 0.01 . 


\section{Results}

All the patients who had been selected for the study attended for the post test assessment with $0 \%$ loss to follow up.

\subsection{Baseline Data}

As this was an extension of two studies published [18] [19], the base line data were same as mentioned in the Table 1 of the previous research [19]. Both groups were approximately similar in the measured socio demographic variables. Female to male ratio in intervention and control groups were 1:5 and 1:3.3 respectively. About 63\% were between 45 to 55 years. Almost all were married except 1 in the study group. Though majority indicated that they were neither current smokers nor current alcohol drinkers, about $40 \%$ and $30 \%$ were social drinkers of alcohol in study and control group respectively.

12 participants from each group were on treatment for less than 1 year while rest were on treatment for more than 1 year. Both groups were almost similar in current drug treatment for the heart disease.

\subsection{Influence of Intervention on Quality of Life}

Except bodily pain in which $\mathrm{p}<0.05$ (68.1 vs 54.8), there was no statistically significant difference in the scores in other components of quality of life between study and control group before the commencement of the study (p > 0.05) [physical function: 59.8 vs 57.3; role physical: 35.0 vs 41.7; general health: 40.7 vs 42.7 ; vitality: 57.7 vs 57.0 ; social functioning: 71.0 vs 74.7 ; role emotional: 37.7 vs 53.3 ; mental health: 61.9 vs 65.3 ]. There was no statistically significant difference between the two groups ( $p>0.05)$ in overall physical health $(52.1$ vs 50.6), overall mental health (53.8 vs 58.6) and total score (54.1 vs 55.9) as well.

There was a statistically significant improvement in all eight components and overall physical health, mental health and total score in the quality of life measured using SF-36 in the study group compared to the control group after the intervention period of one month $(\mathrm{p}<0.01)$ [physical function: $76.0 \mathrm{vs} 50.0$; role physical: 75.8 vs 31.7; body pain: 79.1 vs 56.6; general health: 58.6 vs 42.9 ; vitality: 74.7 vs 51.8 ; social functioning: 86.4 vs 71.9; role emotional: 75.6 vs 45.6; mental health: 78.5 vs 58.8: overall physical health: 72.7 vs 46.5; overall mental health: 74.7 vs 54.1; total score: 75.7 vs 51.2$]$. In the study group, post test scores for all eight components and for overall results were higher than the scores of the pre-test. This increase of the scores observed in the study group after the intervention period was statistically significant $(\mathrm{p}<0.01)$. On the other hand, for the control group, except for body pain and general health, post test scores of the other components were lower when compared to the pre test scores. The slight increase in scores observed in body pain and general health were not statistically significant ( $p>0.05$ ). Reduction of post test scores of the control group for physical function, vitality and mental health were also statistically significant ( $p<0.01, \mathrm{p}<0.05$ and $\mathrm{p}<0.01$ respectively). For all other components including overall results, the reduction in scores were not significant $(p>0.05)$ (Table 1 and Table 2).

Table 1. Effect of intervention on eight components of quality of life.

\begin{tabular}{|c|c|c|c|c|c|c|}
\hline \multirow{2}{*}{ Variable } & \multicolumn{3}{|c|}{ Study group $(\mathrm{N}=30)$} & \multicolumn{3}{|c|}{ Control group $(\mathrm{N}=30)$} \\
\hline & Pre test & Post test & $\mathrm{p}^{*}$ & Pre test & Post test & $\mathrm{p}^{*}$ \\
\hline Mean Physical Function (SD) & $59.8(19.0)$ & $76.0(15.8)$ & $<0.01$ & $57.3(21.4)$ & $50.0(23.3)$ & $<0.01$ \\
\hline Mean Role-Physical (SD) & $35.0(40.8)$ & $75.8(36.8)$ & $<0.01$ & $41.7(39.0)$ & $31.7(38.2)$ & $>0.05$ \\
\hline Mean Body Pain (SD) & $68.1(22.1)$ & $79.1(13.4)$ & $<0.01$ & $54.8(2.9)$ & $56.6(29.5)$ & $>0.05$ \\
\hline Mean General Health (SD) & $40.7(18.7)$ & $58.6(15.5)$ & $<0.01$ & 42.7 (21.3) & $42.9(20.6)$ & $>0.05$ \\
\hline Mean Vitality (SD) & $57.7(14.3)$ & $74.7(10.2)$ & $<0.01$ & $57.0(14.8)$ & $51.8(15.7)$ & $<0.05$ \\
\hline Mean Social Functioning (SD) & $71.0(26.0)$ & $86.4(15.8)$ & $<0.01$ & $74.7(22.8)$ & $71.9(25.5)$ & $>0.05$ \\
\hline Mean Role Emotional (SD) & 37.7 (37.9) & $75.6(39.1)$ & $<0.01$ & $53.3(39.8)$ & $45.6(45.1)$ & $>0.05$ \\
\hline Mean Mental Health (SD) & $61.9(18.9)$ & $78.5(15.6)$ & $<0.01$ & $65.3(17.3)$ & $58.8(17.4)$ & $<0.01$ \\
\hline
\end{tabular}

*Paired t test. 
Table 2. Effect of intervention on overall results of quality of life.

\begin{tabular}{ccccccc}
\hline \multirow{2}{*}{ Variable } & \multicolumn{3}{c}{ Study group $(\mathrm{N}=30)$} & \multicolumn{3}{c}{ Control group $(\mathrm{N}=30)$} \\
\cline { 2 - 7 } & Pre test & Post test & $\mathrm{p}^{*}$ & Pre test & Post test & $\mathrm{p}^{*}$ \\
\hline Mean Overall physical health (SD) & $52.1(16.4)$ & $72.7(13.9)$ & $<0.01$ & $50.6(15.9)$ & $46.5(16.3)$ & $>0.05$ \\
Mean Overall mental health (SD) & $53.8(17.5)$ & $74.7(15.0)$ & $<0.01$ & $58.6(15.1)$ & $54.1(18.1)$ & $>0.05$ \\
Mean Total score (SD) & $54.1(17.9)$ & $75.7(14.9)$ & $<0.01$ & $55.9(15.4)$ & $51.2(17.3)$ & $>0.05$ \\
\hline
\end{tabular}

*Paired t test.

\section{Discussion}

With the results of the current study, it suggests that the use of music complementary to the usual management of IHD helped to improve the QoL of patients with IHD significantly. Even though there was no similar published study conducted earlier, observed results of our study supported the results obtained by previous studies conducted to find out the effect of music on heart rate, anxiety and pain in heart disease patients at various settings such as acute care setting, during cardiac catheterization and coronary angiography [21]-[23].

Drug therapy is a major component of treatment of MI. However, it may also induce side-effects which adversely influence quality of life [24]-[27]. With the results of our study, the quality of life of the patients who were on music therapy in addition to medical management improved significantly compared to patients who were only on medical management. Moreover, from our study, no adverse effects due to music listening for a prolonged period were observed and hence this also confirms the current evidence of safety of relaxation music in therapeutic use [14]. This perceived improvement of the QoL in stable angina patients may be due to the significant improvement of severity of symptoms and the state of ischaemiaas observed in the previous parallel studies [18] [19] and hence the effect of music on underlying pathophysiology of myocardial ischaemia. Therefore, this would further help the scientists to understand the pathophysiological phenomenon of the effect of relaxing music. Furthermore, it would help to formulate newer theories for explaining the effect of music such as metabolic shifting which is postulated by scientists in order to find out newer therapies for the treatment of IHD [28] [29].

Due to the lack of previous evidence, the intervention period of the current study was restricted to one month. Similar to most studies conducted elsewhere in the world, our study also observed the effect of music in a smaller sample. If a study is conducted for a longer period in a larger cohort, it would confirm the feasibility and acceptability of music as complementary treatment and its effect on quality of life and cardiac morbidity. Therefore, our study justifies further studies as definitive, large-scale, randomized clinical trials.

\section{Conclusion}

Listening to the music based on Indian classical system twice a day for one month period complementary to usual treatment significantly improved the quality of life of SA patients aged between 45 and 65 years measured by SF-36. A similar improvement did not observe in the control group who were only on prescribed medicines. Therefore, listening to music can be considered as a complementary to regular treatment for SA which is also cost effective.

\section{Acknowledgements}

We thank Professor R. Sooriarachchi, Department of Statistics, University of Colombo, Sri Lanka for the assistance and guidance given in the calculation of the sample sizes for the study, the National Health Research Council, Sri Lanka for supporting financially a part of this study and for giving technical guidance, director of National Hospital, Sri Lanka, head and the staff of Coronary Care Institute, National Hospital, Sri Lanka for giving necessary facilities to conduct the study and all participants of the study for the support given to conduct it.

\section{Competing Interests}

The authors declare that they have no competing interests. 


\section{References}

[1] Shipper, H. (1983) Why Measure Quality of Life? Canadian Medical Association Journal, 128, 1367-1370.

[2] Wenger, N.K., et al. (1984) Assessment of Quality of Life in Clinical Trials of Cardiovascular Therapies. The American Journal of Cardiology, 54, 908-913. http://dx.doi.org/10.1016/S0002-9149(84)80232-5

[3] Wiklund, I., Herlitz, J. and Hjalmarson, A. (1989) Quality of Life in Postmyocardial Infarction Patients in Relation to Drug Therapy. Scandinavian Journal of Primary Health Care, 7, 13-18. http://dx.doi.org/10.3109/02813438909103664

[4] Ecochard, R., et al. (2001) Indicators of Myocardial Dysfunction and Quality of Life, One Year after Acute Infarction. European Journal of Heart Failure, 3, 561-568. http://dx.doi.org/10.1016/S1388-9842(01)00171-4

[5] De Vreede, J.J.M., et al. (1991) Did Prognosis after Acute Myocardial Infarction Change during the Past 30 Years? A Meta-Analysis. Journal of the American College of Cardiology, 18, 698-706. http://dx.doi.org/10.1016/0735-1097(91)90792-8

[6] Schmidt, M., et al. (2012) 25 Year Trends in First Time Hospitalisation for Acute Myocardial Infarction, Subsequent Short and Long Term Mortality, and the Prognostic Impact of Sex and Comorbidity: A Danish Nationwide Cohort Study. BMJ, 2012, 344-356. http://dx.doi.org/10.1136/bmj.e356

[7] Brown, N., et al. (1999) Quality of Life Four Years after Acute Myocardial Infarction: Short Form 36 Scores Compared with a Normal Population. Heart, 81, 352-358. http://dx.doi.org/10.1136/hrt.81.4.352

[8] ICBS Inc. Stress the Silent Killer. http://holisticonline.com/stress/stress_home.htm

[9] Yale Medical Group (2005) Art Therapy, Dance Therapy, Music Therapy, and Imagery. New Haven.

[10] Jyothi, A. (2004) Healing by Music Therapy-Ragas. http://akhandjyoti.org

[11] Chiu, P. and Kumar, A. (2003) Music Therapy: Loud Noise or Soothing Notes? International Paediatrics, 18, $204-208$.

[12] Kumar, P. and Clerk, M. (2001) Clinical Medicine: A Textbook for Medical Students and Doctors. 4th Edition, W.B. Saunders, Edinburgh.

[13] Iriarte Roteta, A. (2003) Music Therapy Effectiveness to Decrease Anxiety in Mechanically Ventilated Patients. Enfermería Intensiva, 14, 43-48.

[14] American Cancer Society (2008) Music Therapy. Find Support and Treatment. http://www.cancer.org/Treatment/TreatmentsandSideEffects/ComplementaryandAlternativeMedicine/MindBodyandSp irit/music-therapy

[15] Luengo-Fernández, R., Leal, J., Gray, A., Petersen, S. and Rayner, M. (2006) Cost of Cardiovascular Diseases in the United Kingdom. Heart, 92, 1384-1389. http://dx.doi.org/10.1136/hrt.2005.072173

[16] Liu, J.L.Y., Maniadakis, N., Gray, A. and Rayner, M. (2002) The Economic Burden of Coronary Heart Disease in the UK. Heart, 88, 597-603. http://dx.doi.org/10.1136/heart.88.6.597

[17] Ministry of Healthcare, Nutrition and Uva-Wellassa Development (2005) Economy and Health: Taking Sri Lanka towards the Global Best. Draft Commission Report, Ministry of Healthcare, Nutrition and Uva-Wellassa Development, Colombo.

[18] Siritunga, S., Wijewardena, K., Ekanayaka, R. and Mudunkotuwa, P. (2014) Effect of Music on State of Ischaemia in Stable Angina: A Randomized Controlled Trial. International Journal of Clinical Medicine, 5, 1173-1179.

[19] Siritunga, S., Wijewardena, K., Ekanayaka, R. and Mudunkotuwa, P. (2013) Can Music Improve the Symptoms of Stable Angina? A Randomized Controlled Trial. Health, 5, 1039-1044. http://dx.doi.org/10.4236/health.2013.56139

[20] Mudunkotuwa, P. (2006) Music Therapy. Siritunga TLSS, Kotta-wa.

[21] White, J.M. (1999) Effects of Relaxing Music on Cardiac Autonomic Balance and Anxiety after Acute Myocardial Infarction. American Journal of Critical Care, 8, 220-230.

[22] Elliott, D. (1994) The Effects of Music and Muscle Relaxation on Patient Anxiety in a Coronary Care Unit. Heart \& Lung, 23, 27-35.

[23] Guzzetta, C.E. (1989) Effects of Relaxation and Music Therapy on Patients in a Coronary Care Unit with Presumptive Acute Myocardial Infarction. Heart \& Lung, 18, 609-616.

[24] Cremona-Barbaro, A. (1983) Propranolol and Depression. The Lancet, 321, 185. http://dx.doi.org/10.1016/S0140-6736(83)92786-1

[25] Burnett, W.C. and Chahine, R.A. (1979) Sexual Dysfunction as a Complication of Propranolol Therapy in Men. Cardiovascular Medicine, 4, 811-815.

[26] Wiklund, I., Herlitz, J. and Hjalmarson, A. (1989) Quality of Life Five Years after Myocardial Infarction. European Heart Journal, 10, 464-472. 
[27] Croog, S.H., Levine, S., Testa, M.A., Brown, B., Bulpitt, C.J., David Jenkins, C., et al. (1986) The Effects of Antihypertensive Therapy on the Quality of Life. New England Journal of Medicine, 314, 1657-1664. http://dx.doi.org/10.1056/NEJM198606263142602

[28] Szwed, H. (2000) The Place of Metabolic Treatment: Metabolic Approach in Heart Failure. American Heart Journal, 139, 5120-5123.

[29] O’Meara, E. and McMurray, J.J.V. (2005) Myocardial Metabolic Manipulation: A New Therapeutic Approach in Heart Failure? Heart \& Lung, 91, 131-132. http://dx.doi.org/10.1136/hrt.2004.041756 